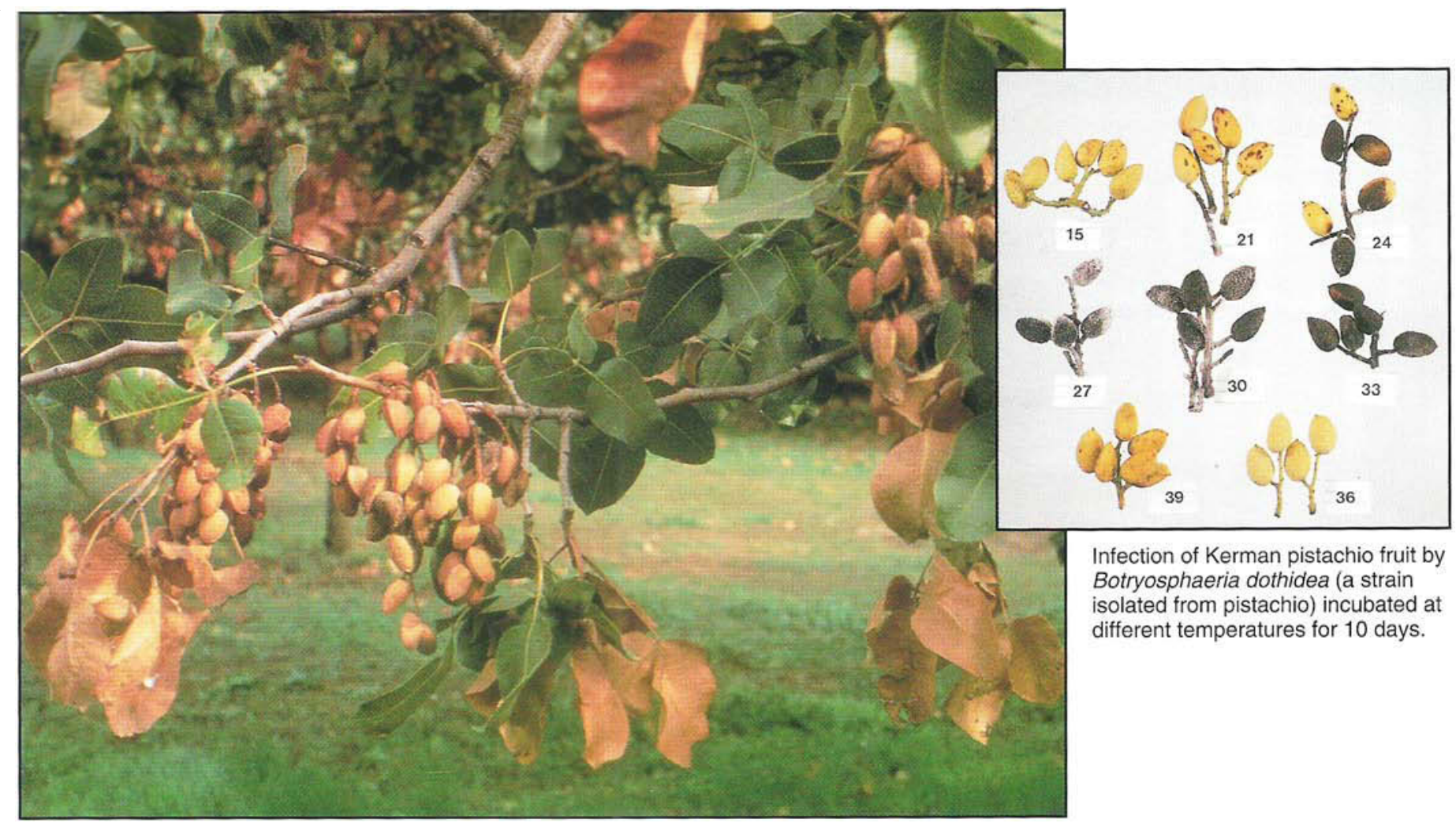

Blighted cluster of pistachio with $B$. dothidea.

\title{
Shorter sprinkler irrigations reduce Botryosphaeria blight of pistachio
}

Themis J. Michailides $\square$ David P. Morgan $\square \quad$ Joseph A. Grant $\square \quad$ William H. Olson

\author{
Botryosphaeria panicle and shoot \\ blight of pistachio caused by the \\ fungus Botryosphaeria dothidea is \\ favored by high temperatures, $80^{\circ}$ \\ to $85^{\circ} \mathrm{F}$, and wetness periods \\ longer than 12 hours. Based on \\ these requirements, the disease \\ becomes severe in late spring and \\ summer when temperatures in- \\ crease and after sprinkler irriga- \\ tions begin. The disease was sub- \\ stantially reduced by shortening \\ sprinkler irrigations from 24 to 12 \\ hours and from 48 to 24 hours in \\ two commercial pistachio orchards \\ in the Sacramento and San \\ Joaquin valleys, respectively.
}

Botryosphaeria panicle and shoot blight of pistachio (Pistacia vera L.), caused by the pycnidial-producing fungus Dothiorella sp. of the ascomycete Botryosphaeria dothidea, is a common disease in orchards in Northern California. Its killing of fruit panicles (clusters) of pistachio has resulted in significant losses (see May-June 1990 California Agriculture). Sources of the spore inoculum are found primarily on blighted rachises, shoots, and petioles retained on the trees. Because structures that produce ascospores have not been found in pistachios, the inoculum. source is thought to be the nonpigmented, one-celled spores (pycnidiospores) that are produced in flasklike pycnidia. Botryosphaeria blight occurrences depend on the availability of pycnidiospores and their spread, and on conditions favoring infection and disease development.
In earlier studies, we observed that Botryosphaeria panicle and shoot blight outbreaks developed in Northern California orchards irrigated by sprinklers for 24 to 48 hours.

High temperatures and extreme wetness favor disease outbreaks during spring and summer and can create substantial losses in yield. Control of the disease in a commercial orchard in Durham, California in 1985 resulted in an estimated $40 \%$ increase in yield. In 1988, however, a severe outbreak of the disease, due perhaps to frequent and long (up to 48 hours) sprinkler irrigation in the same orchard, resulted in destruction of the crop (only $4,500 \mathrm{lb}$ of fresh fruit were harvested from the 20-acre pistachio orchard compared with the normal crop of 35,000 to $40,000 \mathrm{lb}$ ). 
With the exception of benomyl (Benlate $50 \mathrm{WP}$ ), which can be applied once during full bloom, and cupric hydroxide (Kocide 101), no other fungicides are registered in California for control of Botryosphaeria panicle and shoot blight of pistachio. But even if these fungicides were applied, disease control in several orchards with high levels of inoculum would not be economically feasible.

The relationship of disease development to temperature and wetness duration on various host tissues is not clearly understood. It may be possible to predict disease outbreaks, devise more efficient chemical control and cultural control strategies including irrigation manipulation, and therefore significantly reduce losses from the disease in pistachio orchards.

No studies exist on the effects of temperature and wetness duration on Botryosphaeria blight of pistachio. Therefore, this study's objectives were to determine these effects and to help control the disease by reducing the duration of sprinkler irrigation.

\section{Experiments}

Effects of temperature. The effects of various temperatures on spore germination were determined by plating pycnidiospores of $B$. dothidea on four petri dishes containing potato-dextrose agar acidified with lactic acid (APDA) and incubating at 12 different temperatures between $32^{\circ}$ and $102^{\circ} \mathrm{F}$. Fifty spores per dish per temperature were counted after incubation for 7 hours. Growth of B. dothidea was determined also in petri dishes containing APDA by inoculating the dishes centrally with a mycelial plug (3/16 inch in diameter), incubating them at the same 12 different temperatures between $32^{\circ}$ and $102^{\circ} \mathrm{F}$, and recording the colony diameter after 6 days.

To determine the effect of temperature on infection and sporulation of $B$. dothidea on pistachio fruit and leaves, healthy pistachio clusters and leaves of the cultivar Kerman were surface disinfected in a $0.08 \%$ chlorine solution by using household Clorox (Fleming Companies, Inc., Oklahoma City, OK 73126), placed on waxed wire-screens in plastic containers, and allowed to dry. The clusters and leaves were then sprayed with a $10^{5}$ spores per milliliter suspension of $B$. dothidea. To provide a saturated atmosphere, $250 \mathrm{ml}$ of distilled water were poured on the bottom of each container, and containers were incubated at eight different temperatures between $58^{\circ}$ and $102^{\circ} \mathrm{F}$ for 10 days. To maintain continuous wetness periods corresponding to incubation time, clusters and leaves in each container were sprayed with about $5 \mathrm{ml}$ deionized water, using a hand atomizer 1 day after inoculation and every other day thereafter. The percentage of infected fruit and leaf area and fruit- and leaf-bearing pycnidia were recorded 5 and 10 days and 10 and 20 days after inoculation, respectively. In addition, differences in symptomatology of inoculated fruit at different temperatures were recorded. Pycnidial development was observed for up to 20 days incubation.

Effects of wetness. Five current-season shoots bearing seven to eleven leaves and three to six fruit clusters on Kerman pistachio trees were sprayed to run-off with approximately $10 \mathrm{ml}$ of a suspension of $10^{5}$ spores per milliliter of $B$. dothidea. Each shoot was immediately covered with a 10-mil plastic bag that was sprayed inside with distilled water and secured to the shoot with a wet paper towel and masking tape. A brown paper bag was placed over the plastic bag to protect shoots and leaves from sunburn. Shoots were kept wet continuously by opening the bags and rewetting shoots and leaves every 6 to 10 hours, as necessary. Bags were left on for $3,6,9,12,15,18,24,48$, and 72 hours. Shoots similarly inoculated with $B$. dothidea but not covered with plastic and paper bags served as a treatment of 0 -hour wetness. Twenty days after inoculation, disease severity was determined by counting lesions on the leaf blades and classifying the leaves into four disease-severity categories: $0=$ leaves with no lesions, $1=1$ to $5,2=6$ to 15 , and $3=\geq 16$ lesions per leaf. In addition, blighted leaf blades, stems, clusters, fruits, fruits with mature pycnidia, and blighted shoots were determined. The experiment was repeated once and results were averaged.

To determine the effect of interrupted wetness periods on disease development, five to seven mature leaves on each of 20 shoots of Kerman pistachio trees were sprayed to run-off with $10^{5}$ spores per milliliter of $B$. dothidea at 7 a.m. and covered immediately with plastic and paper bags as described previously. At 7 p.m. both plastic and paper bags were removed from all shoots. Following a 12-hour drying period, 15 of the 20 inoculated shoots were sprayed with water, using a handheld sprayer, then covered with both a plastic and a paper bag for 12 hours. This process was repeated four times so that five shoots each were subjected to 12,24 $(12+12), 36(12+12+12)$, and $48(12+12$ $+12+12$ ) hours cumulative wetness periods interrupted by 12-hour dry periods. Twenty shoots, sprayed with distilled water and wetted in a manner similar to the inoculated shoots, served as controls. Disease was recorded 15 to 20 days after the last wetting period and the experiment was repeated once.

Controlling disease with shorter irrigations. An experiment was designed in an orchard in Durham (Butte County) to determine the effects of sprinkler irrigation for 12 hours compared with 24 hours in controlling Botryosphaeria blight. Inoculum of $B$. dothidea was distributed uniformly throughout the orchard ( $82 \%$ of the rachises hanging on the trees had pycnidia of $B$. dothidea). The experiment was set in a completely randomized block design ( 3.4 acres) with three 42-tree replications. The plot was irrigated with under-the-canopy impact sprinklers (of $12^{\circ}$ trajectory angle) that wetted only branches lower than 3 to 4 feet. On the irrigation pipe for each block were 10 sprinklers. Irrigation was controlled by hand shut-off valves connected to the risers of five of the sprinklers for the 42 trees to be irrigated for 12 hours. The irrigation pipe remained at each position for 24 hours, with irrigation starting at 6 a.m. and stopping at 6 p.m. At that time, valves in half of each of the three blocks (three sets of 42 trees) were closed (short duration); irrigation was continued for 12 hours in the other half of each of the three blocks (long duration) before the irrigation pipe was moved to a second position. Irrigation of the experimental plot was completed with three movements of the irrigation pipe within 3 days.

Data on disease were recorded for 10 randomly selected and marked fruit clusters per tree at heights of 4 to 5 feet. At the end of the growing season, during the commercial harvest (September 10-15), fruits from marked clusters were harvested and brought to the laboratory. For each experimental tree, subsamples of 200 nuts and 50 leaves were collected randomly and evaluated for disease (incidences of infected fruit, fruit with pycnidia, infected and blighted rachises, and leaves with disease lesions). The experiment, first performed in 1989, was repeated in the same orchard in 1990 and 1991.

In 1991, a second experimental plot was established in a commercial pistachio orchard in Stockton (San Joaquin County) where the disease had caused significant yield losses during 1987-90. The inoculum of $B$. dothidea was distributed uniformly throughout the orchard and $70 \%$ of the rachises hanging on the trees had pycnidia of the pathogen. This orchard's sprinklers were permanently set in the ground. To control the duration of irrigation in the experimental plot, sprinkler risers were cut and hand shut-off valves were attached on sprinklers in half of the three replicated blocks. In each block were 60 trees and 14 to 16 sprinklers uniformly distributed. By 


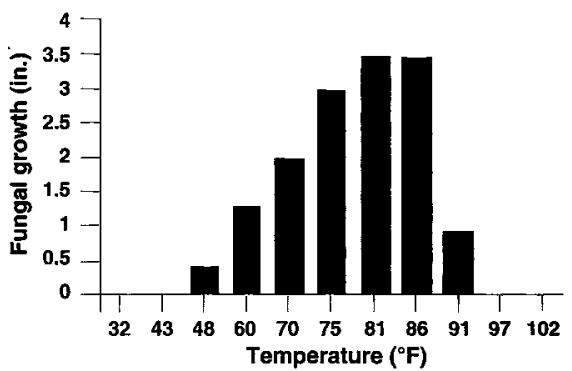

Fig. 1. Effects of temperature on mycelial growth of Botryosphaeria dothidea after 6 days ( $L S D=2 / 16$ inches).

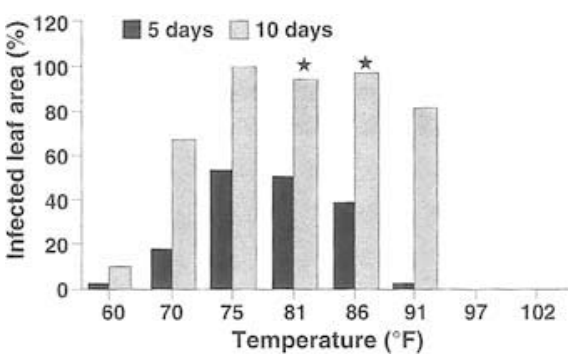

Fig. 2. Effect of temperature on infection of pistachio leaves by Botryosphaeria dothidea after $5(\mathrm{LSD}=21.1 \%)$ and 10 days ( $\mathrm{LSD}=14.3 \%$ ) incubation. The asterisks indicate development of pycnidia on leaves and stems after 10 days.

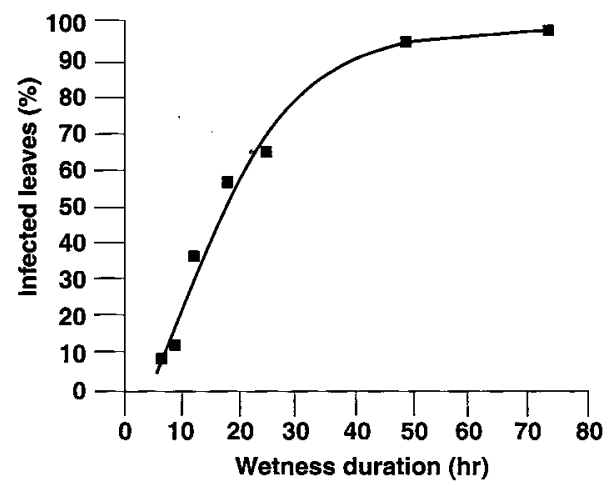

Fig. 3. Effect of continuous wetness duration on infection of leaves of Kerman pistachio by Botryosphaeria dothidea in the field.

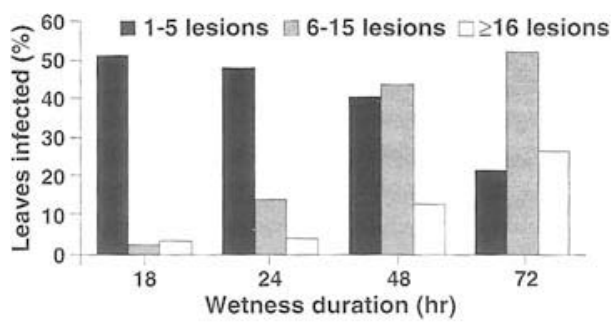

Fig. 4. Effect of continuous wetness duration on severity of Botryosphaeria blight disease on pistachio leaves, determined by counting infection lesions per leaf. shutting off the valves, irrigation in each half of the three blocks (three sets of 30 trees) was kept at 24 hours (short duration); irrigation was continued for 24 more hours in the other three half blocks (three sets of 30 trees) (long duration, grower's schedule).

Leaves collected from each of four trees in the center of each replicated set of trees were evaluated for disease. Because the grower failed to notify us before harvesting the plot, fruit were not evaluated. Statistical analyses for each test year and for both orchards were conducted with ANOVA and comparison of means was done with the Least Significant Difference (LSD) test.

\section{Results}

Effects of temperature. Approximately 75 to $80 \%$ of the spores of $B$. dothidea germinated at $53^{\circ} \mathrm{F}$ after 7 hours' incubation. The percentage of germination increased with temperature; the optimum temperature for pycnidiospore germination was $75^{\circ}$ to $97^{\circ} \mathrm{F}$. At $97^{\circ}$ and $100^{\circ} \mathrm{F}$, the germ tubes of germinated pycnidiospores did not grow more than the length of spores and failed to develop colonies. At $74^{\circ}$ to $86^{\circ} \mathrm{F}$, pycnidiospores of $B$. dothidea germinated within 1.5 to 2.0 hours.

The pathogen grew best at $82^{\circ}$ to $86^{\circ} \mathrm{F}$ (fig. 1). Similarly, optimum temperatures for disease and pycnidia development were $80^{\circ}$ to $91^{\circ}$ and $86^{\circ} \mathrm{F}$, respectively. At $70^{\circ} \mathrm{F}$, several lesions developed on fruit but remained small after 10 days; at $75^{\circ}$ to $91^{\circ} \mathrm{F}$, lesions coalesced and caused fruit blight (see photo p. 28). Temperature effects on $B$. dothidea can explain why the disease becomes severe in late spring and summer when orchard temperatures may reach $80^{\circ}$ to $91^{\circ} \mathrm{F}$.

Optimum temperature for disease development on leaves ranged from $75^{\circ}$ to $85^{\circ} \mathrm{F}$, as determined by the size of the infected leaf area after 10 days of incubation (fig. 2). Pycnidia were not evident at any temperature after 5 days, but they were present on leaves incubated at $81^{\circ}$ and $86^{\circ} \mathrm{F}$ after 10 days, and on those at $70^{\circ}$ and

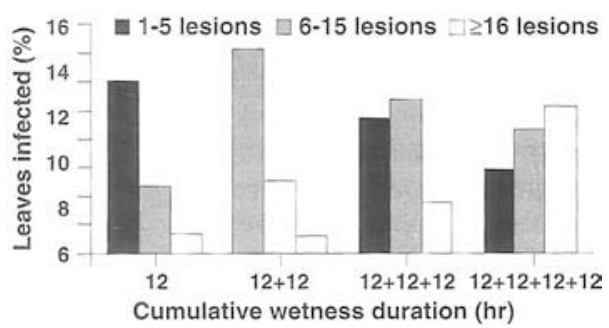

Fig. 5. Effect of interrupted wetness periods on the severity of Botryosphaeria blight on pistachio leaves inoculated with Botryosphaeria dothidea (12-hour wetness periods were interrupted by a 12 -hour dry period). $75^{\circ} \mathrm{F}$ after 15 days; a few developed at $60^{\circ} \mathrm{F}$ after 20 days. Although leaf infection occurred at $91^{\circ} \mathrm{F}$, pycnidia were not formed after 20 days. Therefore, optimum temperature for pycnidia development on leaves and stems was $81^{\circ}$ to $86^{\circ} \mathrm{F}$, temperatures that are common in pistachio orchards in late spring and during summer.

Effects of wetness. No leaves of Kerman pistachio showed any symptoms after 0 to 3 hours wetness and only 8 and $12 \%$ of the leaves were infected after 6 and 9 hours of wetness, respectively (fig. 3). However, 36 to $66 \%$ and 97 to $100 \%$ of the leaves were infected when they were kept wet for 12 to 24 and 48 to 72 hours, respectively (fig. 3 ).

The severity of the disease also increased with wetness periods of 18 to 72 hours. The longer the wetness period, the higher the incidence of leaves with multiple lesions per leaf (fig. 4); more leaves and petioles were blighted after 48 to 72 hours of wetness than after 18 to 24 hours of wetness.

Measurable amounts of infected fruits occurred with 18 hours of continuous wetness and increased significantly with longer periods of wetness. For instance, with 18 to 24 hours of wetness, 8 to $21 \%$ of fruit clusters and 15 to $27 \%$ of fruits were blighted and 2 to $5 \%$ of the fruit had mature pycnidia. With 48 to 72 hours, however, 40 to $100 \%$ of fruit clusters and 61 to $89 \%$ of the fruits were blighted, and 11 to $18 \%$ of them developed mature pycnidia.

The percentage of infected leaves increased with cumulative 12-hour wetness periods interrupted by a 12-hour dry period and the number of lesions per leaf (disease severity index) increased with three or four 12-hour cumulative wetness periods (fig. 5). For instance, with one or two 12-hour wetness periods, only up to $4 \%$ of leaves ( $14 \%$ of the infected leaves) had more than 10 lesions per leaf but with three or four 12-hour wetness periods, 7 to $18 \%$ of leaves ( 30 to $65 \%$ of the infected leaves) had more than 10 lesions per leaf, respectively (fig. 5).

Controlling disease with shorter irrigations. In the experimental plot in Butte County in 1989, trees in blocks irrigated for 24 hours per irrigation had $31 \%$ infected fruit; those in blocks irrigated for 12 hours had only $20 \%$ (results not shown). In 1990, when disease levels were higher in general, the short duration irrigation resulted in trends for lower disease levels. For instance, $60 \%$ of the fruit on trees in blocks irrigated for 24 hours were infected in comparison with $48 \%$ of fruit collected from trees in blocks irrigated for 12 hours (table 1). Similar trends were recorded for fruit with pycnidia and infected rachises with 12 hours of irrigation. Levels of blighted rachises, infected leaves, and dis- 
ease severity of leaves were not affected. In 1991, however, reducing irrigations to 12 hours significantly decreased the percentages of infected fruit, fruits bearing and infected leaves. In addition, fewer lesions (lower disease severity index) developed on leaves collected from trees irrigated for 12 hours than from trees irrigated for 24 hours (table 1).

In the pistachio orchard in San Joaquin County, where only leaves could be evaluated for disease because fruit was harvested before disease ratings were made, the percentage of infected leaves was $37 \%$ in trees irrigated for 24 hours compared with $97 \%$ from trees irrigated for 48 hours. Furthermore, about five times fewer lesions of $B$. dothidea developed per infected leaf in trees irrigated for 24 hours than in trees irrigated for 48 hours (table 1 ).

\section{Conclusions}

This study's results indicate that both directly affect infection of pistachio by $B$. dothidea. Optimum temperatures for disease development $\left(80^{\circ}\right.$ to $\left.85^{\circ} \mathrm{F}\right)$ and sporulation $\left(85^{\circ} \mathrm{F}\right)$ on pistachio fruits and leaves corresponded closely to those $\left(80^{\circ}\right.$ to $\left.85^{\circ} \mathrm{F}\right)$ for mycelial growth and pycnidiospore germination of $B$. dothidea. This explains why Botryosphaeria panicle and shoot blight of pistachio become most severe during summer and early fall. Air temperatures of $80^{\circ}$ to $91^{\circ} \mathrm{F}$ are common during summer and early fall in all pistachiogrowing areas in California. This study also showed that $B$. dothidea infected sprayed with a spore suspension of the fungus. Previously, it was shown that $B$. pycnidia, infected and blighted rachises, temperature and the duration of wetness unwounded pistachio fruits and leaves

dothidea spores penetrated through fruit lenticels and leaf stomata and caused fruit and leaf infections. In contrast, in other fruits, such as apples, wounding is necessary for fruit infection by $B$. dothidea.

Fruits and leaves inoculated with a $10^{5}$ spores $/ \mathrm{ml}$ spore suspension of $B$. dothidea and incubated at $97^{\circ}$ or $102^{\circ} \mathrm{F}$ were not infected, probably because pycnidiospores of $B$. dothidea failed to develop viable colonies even though they germinated at these high temperatures.

Under favorable wetness conditions, such as long irrigation periods, temperatures after fruit and leaf inoculation significantly influenced the levels and intensity of infection and the development of pycnidia. In commercial pistachio orchards, pycnidia on fruits and leaves infected by $B$. dothidea were first noticed in August (when daily maximum, minimum, and average temperatures ranged from $80^{\circ}$ to $102^{\circ} \mathrm{F}, 50^{\circ}$ to $65^{\circ} \mathrm{F}$, and $66^{\circ}$ to $80^{\circ} \mathrm{F}$, respectively, recorded about 2 miles south of the pistachio orchard in Butte County). From August through early September pycnidia development have led to disease outbreaks in pistachio orchards in Northern California.

Although pycnidiospores of $B$. dothidea can germinate within 1.5 to 2 hours after a wetness period is initiated at $73^{\circ}$ to $85^{\circ} \mathrm{F}$, the majority of them did not penetrate until after 12 hours. With longer wetness periods, significantly greater percentages of fruits were infected or blighted, larger numbers of lesions per leaf developed, and infection of petioles and leaf blight occurred, indicating that under such conditions the disease can cause significant fruit losses and leaf blight that leads to tree defoliation. Increased disease incidence and

TABLE 1. Effects of reducing duration of sprinkler irrigation on Botryosphaeria panicle and shoot blight of pistachio caused by Botryosphaeria dothidea in an orchard in Butte County $\left(1989^{\star} 1990\right.$, and 1991) and in another in San Joaquin County (1991)

\begin{tabular}{|c|c|c|c|c|c|c|c|c|}
\hline Year & Orchard & $\begin{array}{l}\text { Duration of } \\
\text { irrigation }\end{array}$ & $\begin{array}{c}\text { Infected } \\
\text { fruit }\end{array}$ & $\begin{array}{l}\text { Fruit with } \\
\text { pycnidia }\end{array}$ & $\begin{array}{l}\text { Infected } \\
\text { rachises }\end{array}$ & $\begin{array}{l}\text { Blighted } \\
\text { rachises }\end{array}$ & $\begin{array}{l}\text { Infected } \\
\text { leaves }\end{array}$ & $\begin{array}{c}\text { Leaf } \\
\text { disease } \\
\text { indexๆ }\end{array}$ \\
\hline & & $h$ & $\% t$ & $\% t$ & $\% \neq$ & $\% \neq$ & $\% \S$ & \\
\hline $\begin{array}{l}1990 \\
\text { (LSD) }\end{array}$ & Butte Co. & $\begin{array}{l}24 \\
12\end{array}$ & $\begin{array}{c}59 . \mathrm{a} \# \\
47.7 \mathrm{a} \\
(13.6)\end{array}$ & $\begin{array}{l}17.3 \mathrm{a} \\
12.8 \mathrm{a} \\
(5.8)\end{array}$ & $\begin{array}{c}64.4 a \\
53.9 \mathrm{a} \\
(14.4)\end{array}$ & $\begin{array}{c}23.1 \mathrm{a} \\
18.0 \mathrm{a} \\
(12.2)\end{array}$ & $\begin{array}{c}37.5 \mathrm{a} \\
38.1 \mathrm{a} \\
(11.5)\end{array}$ & $\begin{array}{r}0.85 a \\
0.87 a \\
(0.58)\end{array}$ \\
\hline $\begin{array}{l}1991 \\
\text { (LSD) }\end{array}$ & Butte Co. & $\begin{array}{l}24 \\
12\end{array}$ & $\begin{array}{l}62.0 \mathrm{a} \\
19.2 \mathrm{~b} \\
(23.0)\end{array}$ & $\begin{array}{r}17.4 \mathrm{a} \\
4.9 \mathrm{~b} \\
(11.1)\end{array}$ & $\begin{array}{c}68.9 \mathrm{a} \\
16.8 \mathrm{~b} \\
(9.8)\end{array}$ & $\begin{array}{c}26.6 \mathrm{a} \\
1.0 \mathrm{~b} \\
(8.7)\end{array}$ & $\begin{array}{c}74.0 \mathrm{a} \\
30.5 \mathrm{~b} \\
(15.1)\end{array}$ & $\begin{array}{c}1.41 a \\
0.43 b \\
(0.48)\end{array}$ \\
\hline $\begin{array}{l}1991 \\
\text { (LSD) }\end{array}$ & San Joaquin Co. & $\begin{array}{l}48 \\
24\end{array}$ & $\begin{array}{l}\ldots \cdot \cdot \\
\ldots\end{array}$ & $\begin{array}{l}\ldots \\
\ldots\end{array}$ & $\begin{array}{l}\ldots \\
\ldots\end{array}$ & $\begin{array}{l}\ldots \\
\ldots\end{array}$ & $\begin{array}{c}96.8 \mathrm{a} \\
37.0 \mathrm{~b} \\
(21.3)\end{array}$ & $\begin{array}{c}2.26 a \\
0.54 b \\
(0.40)\end{array}$ \\
\hline
\end{tabular}

'Twenty percent of the fruit from the trees irrigated for 12 hours were infected and $31 \%$ from trees irrigated for 24 hours $(P=0.10)$.

†Averages of six 200 -fruit replications.

$\ddagger$ Averages of six samples of 30 to 50 rachises.

$\S$ Fifty leaves per tree were evaluated.

qDisease index was based on four ( 0 to 3 ) disease severity categories (see text for details)

\#Different letters indicate significant differences $(P<0.05)$.

**Not determined because of prescheduled harvest by the grower. severity with increased duration of wetness have been reported for several other leaf and fruit diseases. For instance, longer wetness periods increased the number of lesions caused by Wilsonomyces carpophilus (Stigmina carpophila), causing shothole disease on leaves of almond in California.

Because rains usually do not occur during summer and early fall in California and infection by $B$. dothidea can only come about, therefore, in sprinkler irrigation, control of Botryosphaeria blight is possible by adjusting irrigations to minimize leaf wetness periods. Information on wetness duration obtained from the experiments can be utilized by growers to manage disease. Irrigation records for the Butte County commercial orchard indicate how critical the duration of wetness periods are in causing disease epidemics. In 1986 , when duration of irrigations ranged from 22 to 46 hours, $76 \%$ of the pistachio fruit were infected. In 1988, when the grower applied three preharvest irrigations of 44 hours each, $99 \%$ of the fruit was lost because of $B$. dothidea, the highest loss ever recorded in this orchard. Reducing the duration of irrigations to 12 hours showed trends toward reducing disease in 1989 and 1990. The effects of reducing the duration of irrigation in 1989 and 1990 were not significant probably because of the frequent humid nights that occurred in late August and early September in those years. Recordings from hygrothermographs (instruments that can record both temperature and relative humidity) placed in the orchard indicated that the relative humidity reached the $100 \%$ level for several hours during at least seven nights in this orchard. Therefore, when ambient relative humidity is lower than $100 \%$ during August-September (before maturation of pistachio), reducing irrigation periods will result in significantly lowering levels of disease, as shown in the 1991 experiments.

Similarly, control of Botryosphaeria panicle and shoot blight of pistachio is possible in orchards with permanent sprinkler-irrigation systems. Disease incidence and severity were even greater in San Joaquin County orchard than that in Butte County (table 1), probably because duration of irrigations was longer (48 hours). Reducing irrigation time to 24 hours did not seem to stress the trees, at least not to the levels of stress that have reportedly favored peach gummosis disease or diseases of other woody plants caused by $B$. dothidea.

Results obtained from these studies can be utilized for predicting disease incidence and severity that occur under certain environmental conditions and methods of irrigating orchards. For instance, orchards irrigated for 48 hours nonstop are at high 


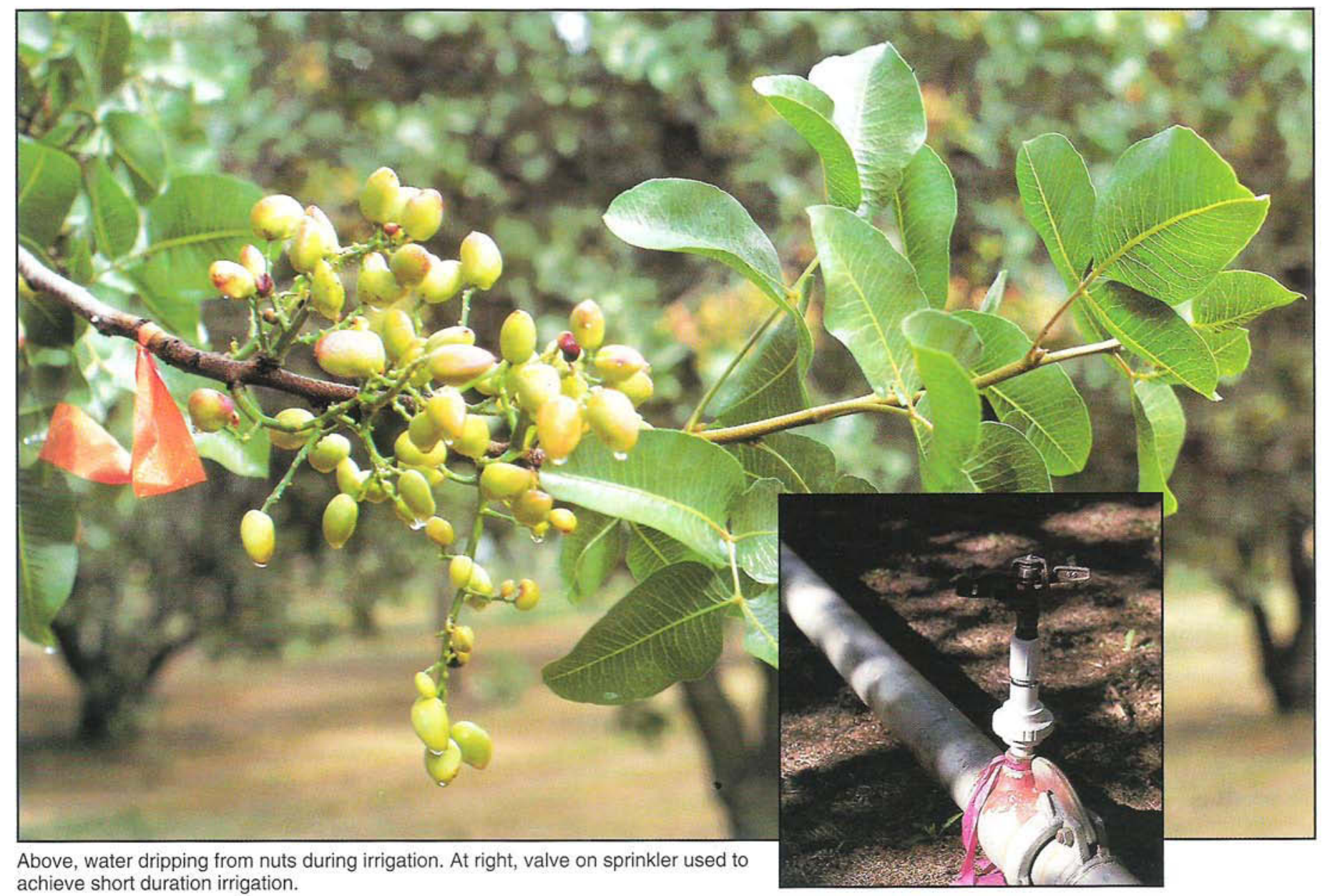

risk to be damaged by the disease, a situation common in pistachio orchards in Butte and Tehama counties. In contrast, in orchards irrigated by drip or microjet sprinklers (which do not wet tree canopies or significantly increase relative humidity in an orchard) the disease poses no major threat. Therefore, although $B$. dothidea has been isolated in pistachio orchards throughout California, it caused major crop losses only in Northern California, where sprinkler irrigations lasting 24 to 48 hours are common.

Temperatures in an orchard cannot be controlled to any great extent, but disease can be controlled with a practice over which growers have some control - that is, the duration of irrigation. In the

Durham orchard, trees irrigated for 24 hours received 29.0,24.3, and 29.7 inches of water; those irrigated for 12 hours received 15.8, 13.5, and 16.2 inches of water in 1989, 1990, and 1991, respectively. The approach to controlling Botryosphaeria blight is timely because, due to California's 6-year drought, sustained or controlled deficit irrigations (irrigations not fulfilling the $100 \%$ evapotranspiration requirements) have been studied and are presently recommended for pistachios in California.
T. J. Michailides is Associate Research Plant Pathologist, and D. P. Morgan is Staff Research Associate, Department of Plant Pathology, UC Berkeley, located at the Kearney Agricultural Center, Parlier; J. A. Grant is Farm Advisor, San Joaquin County, and W. $H$. Olson is Farm Advisor, Butte County.

The authors thank F. \& M. Montgomery (Almond Orchards, Durham, California), J. Bradford (Ballards Orchards Corporation, Vina, California), and R. Schrum, pistachio grower, for their cooperation and permission to manipulate irrigation duration in their orchards. This research was supported by funds from the California Pistachio Commission.

\section{CALIFORNIA AGRICULTURE ASSOCIATE EDITORS}

Animal, Avian, Aquaculture and Veterinary Sciences

Richard H. McCapes

(2nd assoc. editor to be announced)

\section{Economics and Public Policy}

Harold O. Carter

(2nd assoc. editor to be announced)

\section{Food and Nutrition}

Eunice Williamson

(2nd assoc. editor to be aninounced)

Human and Community Developmen

Linda M. Manton

Karen P. Varcoe
Land, Air \& Water Sciences

Garrison Sposito

Henry J. Vaux, Jr.

Natural Resources

Daniel W. Anderson

John Helms

Richard B. Standiford

Pest Management

Thomas C. Baker

(2nd assoc. editor to be announced)

\section{Plant Sciences}

Calvin O. Qualset

G. Steven Sibbett 